\title{
Removal of methyl orange from from aqueous solutions using of PANI and PANI@Activated Carbon: Preparation, characterization, regeneration and comparative study
}

\author{
Amina Bekhoukh \\ University of Mustapha Stambouli Mascara \\ Imane Moulefera \\ University of Mustapha Stambouli Mascara
}

Fatima Zohra Zeggai

University of Mustapha Stambouli Mascara

Benyoucef Abdelghani ( $\square$ abdelghani@ua.es )

Faculté des Sciences et Thechnologie https://orcid.org/0000-0002-0247-2808

Khaldoune Bachari

Faculté des Sciences et Thechnologie

\section{Research Article}

Keywords: Polyaniline, Activated Carbon, Hybrid Materials, Methyl Orange, Adsorption

Posted Date: May 17th, 2021

DOl: https://doi.org/10.21203/rs.3.rs-529269/v1

License: (c) (1) This work is licensed under a Creative Commons Attribution 4.0 International License.

Read Full License 
1 Removal of methyl orange from from aqueous solutions using of PANI and

2 PANI@Activated Carbon: Preparation, characterization, regeneration and

3

4

5

6

7

\section{comparative study}

A. Bekhoukh ${ }^{1}$, I. Moulefera ${ }^{2,3}$, F.Z. Zeggai ${ }^{4}$, A. Benyoucef ${ }^{2}{ }^{*}$, K. Bachari $^{4}$

(1)

${ }^{1}$ Faculty of Science and Technology, University of Mustapha Stambouli Mascara, Algeria ${ }^{2}$ University of Mustapha Stambouli Mascara, LMAE Laboratory, Algeria

${ }^{3}$ Departamento de Ingeniería Química, Facultad de Ciencias, Universidad de Málaga, (1) Andalucía TECH, Málaga, Spain, ${ }^{4}$ CRAPC, BP 248, 16004 Bou Ismaïl, Algeria.

*Corresponding author : abdelghani@ua.es or a.benyoucel@univ-mascara.dz 


\section{Abstract}

This work investigated the elimination of Methyl Orange (MO) using a new adsorbent prepared from Activated Carbon (AC) with polyaniline reinforced by a simple oxidation chemical method. The prepared materials were characterized using XRD, TGA, FTIR and nitrogen adsorption isotherms. Furthermore, PANI@CA highest specific surface area values (near $332 \mathrm{~m}^{2} \cdot \mathrm{g}^{-1}$ ) and total mesoporous volume (near $0.038 \mathrm{~cm}^{3} \cdot \mathrm{g}^{-1}$ ) displayed the better MO removal capacity (192.52 mg. $\mathrm{g}^{-1}$ at $298 \mathrm{~K}$ and $\mathrm{pH}$ 6.0), which is outstandingly higher than that of PANI (46.82 mg.g $\left.{ }^{-1}\right)$. Besides, the process's adsorption, kinetics, and isothermal analysis were examined using various variables such as $\mathrm{pH}, \mathrm{MO}$ concentration and contact time. To pretend the adsorption kinetics, various kinetics models, the pseudo first- and pseudo secondorders, were exercised to the experimental results. The kinetic analysis revealed that the pseudo second order rate law performed better than the pseudo first order rate law in promoting the formation of the chemisorption phase. In the case of isothermal studies, an analysis of measured correlation coefficient $\left(R^{2}\right)$ values showed that the Langmuir model was a better match to experimental results than the Freundlich model. By regeneration experiments after five cycles, acceptable results were observed.

Keywords: Polyaniline; Activated Carbon; Hybrid Materials, Methyl Orange, Adsorption. 


\section{Introduction}

Various dyes are applied for products in the textile industry and paint, food, paper, cosmetics, plastic, leather factories and rubber synthetic organic dyes. The products throw into the environment by wastewater have unwanted impacts on nature and living microorganisms $[1,2]$. These dyes are hazardous and toxic and can cause diseases, such as cancer and genetic transition in all creatures [3-5]. Amongst these toxic dyes, methyl orange (MO) belongs to anionic class and it has been widely utilized in the above-industry. So, its removal from different aqueous wastes is required and important. Generally, membrane filtration, precipitation, coagulation, biological treatment, adsorption, ion exchange, electrochemical process, photocatalytic degradation and ozonation are adequate candidates for such purpose [613].

Conducting polymers materials (CPM) having hybrid $\pi$-conjugated bonds has attracted interest from many researchers in scientific and industrial fields in recent times. Conductive polymeric, such as polyaniline, polypyrrole, poly(p-phenylene) and polythiophene, have usually been applied in technological investigations and in several applications as rechargeable batteries [14, 15], sensors [16] diodes, microelectronic devices and in transistors and [17, 18]. Amongst the CPM, PANI receiving a great deal of attention due to their good environmental stability, simple synthesis, ability to dope with protonic acids, and the being of amine groups in its structure and higher electrical conductivity [19].

The existence of amine-imine groups in PANI is the active species for the dye remove. Accordingly, it is widely reported of PANI used as adsorbent of dye in literature review, e.g. Mahi et al. [20], recorded PANI and PANI@OFI to elimination the Acid orange 10 (named 
OrangeG) and Tanzifi et al. [2], eliminated the MO by PANI. Whereas that, Li et al., investigated the removal of Methylene-Blue, Congo-Red and Rhodamine-(B) by PANI as adsorbent [21, 22], confirming the big capacity for eliminate the diverse dyes types by PANI.

However, employing PANI as nanoadsorbent can offer some defies such as aggregation, problem to separate from aqueous solution and thus complicating the regeneration of this adsorbent [23]. Thereby, it is needful to find a method to protect the PANI, overcome the aforesaid difficulties and enhance the efficiency of the PANI without compromise diffusion of effluent. In this consideration, the use of adsorbents based on conductive polymer with diverse inorganic products has proven to be promising for the high removal of organic and inorganic pollutants. Many works have been made to modify the used of PANI and its PANI@inorganic hybrids for the adsorption of pollutants from water. Further, Activated carbon (AC) was vastly used to water and wastewater processing because of its well-developed porosity, high surface area, high mechanical strength, hydrophobic surface and many precursors [24], which make it become an ideal backing during recent nanoadsorbent elaboration processes.

The essential objectives of these studies were to develop a new adsorbent PANI@AC and evaluate its effectively removing Methyl Orange from aqueous solution. The prepared adsorbents were characterized using XRD, FTIR, TGA and BET analyses. Moreover, a series of batch tests was determined to estimate the MO removal performance, initial MO concentration, $\mathrm{pH}$ and the effects of contact time. Batch and continuous fixed bed kinetics experimental data were estimated with different conventional models.

\section{Experimental}

\subsection{Materials}


Methyl Orange (MO), Aniline (ANI), Ammonium persulfate (APS), Hydrochloric acid 37\%, Ethanol 96\%, and Methylsulfinylmethane (DMSO) 98\% made by Merck Company. The commercial activated carbon (AC) chosen for this investigation has been bought by Waterlink Suctliffe Carbons. Before the experiences, the AC material were washed multiple times with $\mathrm{H}_{2} \mathrm{O}$ and dried at $80{ }^{\circ} \mathrm{C}$ for $3 \mathrm{~h}$. Deionized $\mathrm{H}_{2} \mathrm{O}$ was used for all experiments.

\subsection{Measurements}

Fourier Transform Infrared Spectrometer (Bruker-Inc., Model-Alpha spectrophotometer) was used to identify the functional groups. X-ray Diffraction (Bruker-CCD Apex instrument) was used to identify the structural properties of samples. Measurement of the specific surface area was performed by $\mathrm{N}_{2}$ adsorption \& desorption analysis (BET-BELSORP MINI II). UV-Spectrophotometer (Hitachi U-3000 Spectrophotometer) was applied to measure the MO concentration. Thermogravimetry Analyze (TGA) (Hitachi STA7200 Instrument) was used to determine the thermal and/or oxidative stabilities of materials as well as their [25, 26].

\subsubsection{Porous texture characterization}

The microscopic pore structure property of AC sample was characterized by physical adsorption of gases (nitrogen at 77K \& Carbon dioxide at 273K) using Micromeritics ASAP$2020 \mathrm{M}$ system. Correspondingly, $\mathrm{N}_{2}$ adsorption is mainly to gain the information on total micropores volume $\left(\mathrm{V}_{\mathrm{DR}}\right)$ applying the Dubinin-Radushkevich (DR) formula and to determine the specific surface area according to the BET law (SBET) [20, 27].

\subsection{Synthesis of adsorbent materials}

Adsorbent materials were synthetized by in-situ polymerization of ANI $220 \mathrm{~mol}$ in $\mathrm{HCl}$ dispersions of the AC. Firstly; the AC was dried at $353 \mathrm{~K}$ for one day to eliminate humidity. 
Next, $1.0 \mathrm{~g}$ of $\mathrm{AC}$ was added to a $1 \mathrm{M} \mathrm{HCl}$ and sonicated using probe ultrasound for $30 \mathrm{~min}$. Thereafter, the ANI was added, and the solution was sonicated also $30 \mathrm{~min}$ to elevate the substitution of monomer inside AC pores. Finally, APS dissolved in $1 \mathrm{M}$ of $\mathrm{HCl}$ was added dropwise to solution of ANI with AC under constant stirring (the molar of APS to ANI was 1:1). The preparation was carried out at $298 \mathrm{~K}$ for $24 \mathrm{~h}$. The PANI@AC produced were filtered, washed with deionized water and then dried in oven at $343 \mathrm{~K}$ for $24 \mathrm{~h}$ [25-28]. The pure PANI was synthetized in similar way mentioned above but in absence of AC.

\subsection{Adsorption tests}

The $1000 \mathrm{mg} . \mathrm{L}^{-1}$ stock MO solution was prepared through dissolving $1.0 \mathrm{~g}$ of $\mathrm{MO}$ powder in $1 \mathrm{~L}$ of deionized water. Then, through dilution, the solution was prepared with the required initial concentrations of dye from 2 to $500 \mathrm{ppm}$. Generally, the proposed pathway of synthesis and of MO removal by PANI@AC was depicted in Fig. 1.

\subsubsection{Batch adsorption experiments}

Kinetics of batch adsorption experiments were considered to investigate the time to reach equilibrium and carried out at $\mathrm{MO}$ solution concentrations of $2 \mathrm{ppm}, 5 \mathrm{ppm}, 10 \mathrm{ppm}$, 20ppm, 100ppm, 200ppm and 500ppm with $10 \mathrm{mg}$ of the synthetized adsorbent in the ambient temperature. The dye solution concentration was determined by UV-Vis spectrophotometer in wavelength of maximum absorbance of $464 \mathrm{~nm}$. A calibration curve of concentration-vsabsorbance was determined by Beer-Lambert's equation. The quantity of MO adsorbed at equilibrium, $Q_{e q}\left(\mathrm{mg}_{\mathrm{g}} \mathrm{g}^{-1}\right)$, was established applied formula below:

$$
Q_{e q}=\frac{\left(C_{0}-C_{e q}\right) V}{m}
$$


129 Here, $m(\mathrm{~g})$ is the amount of adsorbent; $C_{0}$ and $C_{e q}\left(\mathrm{mg} . \mathrm{L}^{-1}\right)$ are the initial and equilibrium concentrations of $\mathrm{MO}$, respectively; $\mathrm{V}(\mathrm{mL})$ is $\mathrm{MO}$ volume; $Q_{e q}\left(\mathrm{mg} \mathrm{g}^{-1}\right)$ is the quantity of $\mathrm{MO}$ adsorbed by adsorbent at time t.

The needful properties of the Langmuir model can be proved in terms of a dimensionless separation factor $\left(R_{L}\right)$ are obtained by the following:

$$
R_{L}=\frac{1}{1+K_{L} C_{0}}
$$

Here, $C_{0}$ : highest initial adsorbate concentration $\left(\mathrm{mg} . \mathrm{L}^{-1}\right)$ and $K_{L}$ : Langmuir constant $\left(\mathrm{L} . \mathrm{mg}^{-1}\right)$. $R_{L}$ shows the state of isotherm to be either unfavorable for $R_{L}>1$, favorable $\left(0<R_{L}<1\right)$, linear for $R_{L}=1$ or irreversible for $R_{L}=0$ [29].

In conformity with the Freundlich isotherm, the adsorbed molecules cannot be greater than of active sites number, and the layer formed on nanoadsorbent surface authorized development of following layers [30]. The isotherm is determined by the next law:

$$
\log Q_{e q}=\log K_{F}+\frac{1}{n} \log C_{e q}
$$

Here, $K_{F}:$ Freundlich-constant $\left(\mathrm{L}^{\mathrm{mg}}{ }^{-1}\right) ; 1 / n$ : intensity of adsorption constant ; $Q_{e q}$ : adsorption capacity of $\mathrm{MO}$ adsorbed at equilibrium $\left(\mathrm{mg} \cdot \mathrm{g}^{-1}\right.$ ) and $C_{e q}$ : equilibrium concentration of $\mathrm{MO}\left(\mathrm{mg} \cdot \mathrm{L}^{-1}\right)$.

Adsorption kinetic isotherms were used to describe adsorptive molecules transfer behavior and investigate factors affecting reaction rate. In the current work, pseudo first order and pseudo second order kinetics models were applied to investigate the batch adsorption performance. 
Pseudo first order:

$$
\log \left(Q_{e q}-Q_{t}=\log Q_{e q}-\frac{k_{l}}{2.303}\right.
$$

Pseudo-second-order:

$$
\frac{1}{Q_{t}}=\frac{1}{k_{2} Q_{e q}^{2}}+\frac{1}{Q_{e q}} t
$$

Here, $Q_{e q}$ is quantity of MO adsorbed at equilibrium $\left(\mathrm{mg}^{-\mathrm{g}^{-1}}\right) ; Q_{t}$ is quantity of MO on the surface of the adsorbent at every time $t\left(\mathrm{mg} \cdot \mathrm{g}^{-1}\right)$ and $k$ is equilibrium speed-constant of the pseudo first order.

\subsubsection{Adsorbent regeneration test}

From the operational perspective and environmental goals, adsorbent regeneration and reuse constitute one of the important and innovative aspects of economic feasibility. To investigate adsorbent regeneration performance, $0.1 \mathrm{~g}$ of the prepared adsorbent was poured in $25 \mathrm{ml}$ of MO solution with a concentration of 100ppm at $298 \mathrm{~K}$ under stirring for $2 \mathrm{~h}$. The residue dye solution concentration was determined by UV-Vis spectrophotometer and MO adsorption capacity by adsorbent was investigated.

After that, the adsorbent was removed from the solution and placed in $40 \mathrm{ml}$ of nitric acid 0.05 molar as elution solvent on a stirrer for 10 minutes. Afterwards, the adsorbent was washed with deionization $\mathrm{H}_{2} \mathrm{O}$ and placed in $\mathrm{MO}$ solution with the same condition and these stages were repeated for 5 times.

\section{Results and Discussion}




\subsection{Adsorbent characterization}

To further characterize micromorphology and molecular structure of the products, XRD, FITR, TGA and BET measurements were carried out. Fig. 2-a show the XRD patterns of the PANI, AC and PANI@AC samples, respectively. The AC shows peaks at around $2 \theta=20.80^{\circ}$, $26.61^{\circ}, 31.25^{\circ}, 33.41^{\circ}, 40.74^{\circ}, 43.43^{\circ}$, and $47.85^{\circ}$ which corresponds to (100), (101), (220), (110), (102), (200) and (112) plane of carbon, respectively. Furthermore, It can be seen that the AC pattern displayed an amorphous halo centered at $2 \theta=25.32^{\circ}$, which indicates to the reflection of the plane (002), a common characteristic of non-crystalline structures such as AC [31]. Moreover, the PANI shows an amorphous background in their XRD patterns because polyaniline is incomplete crystalline. The crystallinity and coherence length of the pure PANI polymer chain orientation can be analyzed by the diffraction peaks at $2 \theta$ values of $8.94^{\circ}(001)$, $16.49^{\circ}(011), 20.15^{\circ}(100)$ and $24.90^{\circ}(110)$. All peaks are in good agreement with results by Bekhti et al. [32]. This diffraction peaks are attributed to the vertical and parallel periodicity of the PANI chain, respectively. On the other hand, the PANI@AC product consist of peaks at $2 \theta=20.80^{\circ}$ and $26.61^{\circ}$. Further, the peak of this sample in the observed diffraction profile is almost at around $24.68^{\circ}$ reveals to amorphous type of PANI@ AC.

Fig. 2-b. display the FT-IR spectrum of synthesized PANI, it can be seen a series of characteristic peaks including $\mathrm{C}=\mathrm{C}$ stretching vibration of benzenoid units at $1490 \mathrm{~cm}^{-1}$ and $1576 \mathrm{~cm}^{-1}$ of PANI are presented [25, 32], which makes clear that the PANI is in semioxidation state. The bands at $1296 \mathrm{~cm}^{-1}$ and $1242 \mathrm{~cm}^{-1}$ are attributed to $\mathrm{C}-\mathrm{N}$ stretching vibration of secondary aromatic amino structures [33]. The main characteristic band at 800 $\mathrm{cm}^{-1}$ is belonging to the aromatic $\mathrm{N}-\mathrm{H}$ stretching vibration of secondary aromatic amine bending vibration. Moreover, the main band at $1128 \mathrm{~cm}^{-1}$ is ascribed to the out-of-plane 
bending vibration of $\mathrm{C}-\mathrm{H}$ within the stretching vibration of $\mathrm{C}-\mathrm{N}$ of the secondary aromatic amine structures bending vibration. Besides, the characteristic absorption band appeared at the $1377 \mathrm{~cm}^{-1}$ is related to the bending vibrations of the $\mathrm{C}-\mathrm{H}$ groups. For $\mathrm{AC}$, spectra have similar shape in vibration band features of carbonaceous material and the band at $3387 \mathrm{~cm}^{-1}$ can be associated to $\mathrm{O}-\mathrm{H}$ groups. The band at $1554 \mathrm{~cm}^{-1}$ can be assigned to $\mathrm{C}=\mathrm{O}$ axial deformation . Whereas that, band at $1096 \mathrm{~cm}^{-1}$ can be attributed to $\mathrm{C}-\mathrm{OH}$ (phenolic, ethers). Thereby, there are many functional groups for adsorbing contaminant ions on AC. These functional groups play an important role in removal of pollutant ions. Moreover, the FTIR spectra of PANI@ AC are which fully match PANI spectra. For PANI@AC spectrum, the bands at 1576 and 1495 $\mathrm{cm}^{-1}$ are ascribed to vibrations of the quinoid and benzene rings, respectively. The other characteristic bands at 1301,1126 , and $816 \mathrm{~cm}^{-1}$ can be attributed with the $\mathrm{C}-\mathrm{N}$ stretching of the secondary aromatic amine, aromatic $\mathrm{C}-\mathrm{H}$ in-plane bending and out-of-plane bending vibration, respectively. Furthermore, the band of $\mathrm{AC}$ at $1096 \mathrm{~cm}^{-1}$ are shifted to $1032 \mathrm{~cm}^{-1}$, indicating the interaction between the PANI and the surface of the AC.

The TGA curve of AC, PANI and PANI@AC were showed in Fig. 2c. PANI displayed the initial weight loss $(20.84 \%)$ below $194^{\circ} \mathrm{C}$, which was attributed to the loss of water and solvents molecules. The second weight loss $(32.81 \%)$ in the range from $194{ }^{\circ} \mathrm{C}$ to $408{ }^{\circ} \mathrm{C}$ was due to the removal of structural organic ligands from their frameworks. At $800{ }^{\circ} \mathrm{C}$, the total weight loss of PANI was 67.86\%, while PANI@AC was 54.63\%. The reason is that the presence of polymer on the surface of AC promoted the growth of the crystal. It was concluded that PANI@AC had better thermal stability than PANI, mainly due to the introduction of AC.

With measuring $\mathrm{N}_{2}$ adsorption-desorption isotherms, the pore size distribution, specific surface area and pore volume of AC, PANI and PANI@AC were calculated, and results were 
showed in Fig. 2-d and Table 1. It showed that curves of samples are IV-type isotherms with $\mathrm{H}_{3}$ type hysteresis loops, confirming the presence of mesoporous in the material. Comparing with PANI, the specific, pore size, and pore volume of PANI@AC were significantly increased. The specific surface PANI@AC area was $332 \mathrm{~m}^{2} \cdot \mathrm{g}^{-1}$, which was substantially higher than that of PANI $\left(17.52 \mathrm{~m}^{2} \cdot \mathrm{g}^{-1}\right)$. The pore volume increased from $0.023 \mathrm{~cm}^{3} \cdot \mathrm{g}^{-1}$ to $0.038 \mathrm{~cm}^{3} \cdot \mathrm{g}^{-1}$. These mesoporous structure with large surface area were more favorable to the adsorption of dyes.

\subsection{Adsorption of $\mathrm{MO}$}

\subsubsection{Influence of $\mathrm{pH}$}

The effect the $\mathrm{pH}$ solution has on the MO removal was investigated by changing the reaction solution $\mathrm{pH}$ from 3 to 11 and conserving all other parameters constant by PANI and PANI@AC adsorbents, respectively. Fig. 3-a shows the effect pH has on removal efficiency. It is clear that PANI@AC performed better relative to PANI in the PANI in the adsorption of MO from aqueous solution at various values of $\mathrm{pH}$ studied. In addition, it was showed that both adsorbents realized the best results at $\mathrm{pH} 6$. The elimination rate was low at both lower and higher $\mathrm{pH}$ values. As observed, the PANI has a high potential for MO removal on the $\mathrm{pH}$ between 6 and 8. Further, the MO ions possesses negatively charged at pH 7 (or practically neutral $\mathrm{pH}$ values; between 6 and 8) and display maximum MO removal. Furthermore, as Emeraldine-Salt (ES) and Emeraldine-Base (EB) formulas of the PANI occur at lower acidic and higher basic $\mathrm{pH}$ values respectively, the ES form get passed to EB near $\mathrm{pH} 7$ [34]. Likewise, the MO exist in cationic form and at the same time the PANI has positive charge in the $\mathrm{pH}$ value between 5 and 8 , the maximum removal has been presented in this range of $\mathrm{pH}$ 
values, thanks to the formation of electrostatic force to the gravitational between $\mathrm{MO}$ and adsorbent used.

\subsubsection{Effect of adsorption time on adsorption efficiency}

Fig. 3-b. exhibits a comparison of the MO adsorption capacity and removal efficiency with time. The results showed that the \% removal of dye by PANI increased with increasing time from 10 to $40 \mathrm{~min}$ where reached $17.64 \%$ at $40 \mathrm{~min}$. Thereafter, the $\%$ removal of MO increased to $76.18 \%$ when the time changed from 40 to $60 \mathrm{~min}$. Also, the influence of time on the adsorption capacity of PANI@AC sample toward MO was performed in the time range of 10-120 min. The results showed that the adsorption capacity of the hybrid adsorbent toward dye increased with increasing time from 10 to $60 \mathrm{~min}$ where reached $192.52 \mathrm{mg} . \mathrm{g}^{-1}(77.14 \%)$ at $60 \mathrm{~min}$. Hence, $60 \mathrm{~min}$ is considered the optimum time for the removal of MO using the PANI@AC.

To prepare information about factors affecting reaction rate, it is necessary to determine mechanisms that control the adsorption process such as surface adsorption, chemical reaction, and kinetics assessment infiltration mechanisms. Pseudo first order and pseudo second order models have widely used for investigation of the adsorption process. In Table 2, the parameters related to studied kinetic models are presented. The correlation coefficient $R^{2}$ represents how good these kinetic models fit the removal process. The $R^{2}$ values obtained from kinetic models reveal that the removal process complies more with the pseudo second order kinetic model indicating that chemical adsorption is ratio controlling and adsorption is the result of interaction betwixt functionally groups on the nanoadsorbent surface. Also, the calculated value of $Q_{\text {eq.Cal }}$ obtained from the pseudo second order model is close to the experimental value of $Q_{\text {eq.Exp }}$. 

277 the calculated regeneration efficiencies were $75.79 \%, 69.75 \%, 58.13 \%$ and $40.34 \%$,

Hence, the kinetics of adsorption is best defined by the pseudo second order kinetic model for two adsorbents used in this study.

\subsection{Adsorption isotherms of MO}

Fig. 3-c display the adsorption isotherms of MO by various adsorbents calculated at 298 K. The matching result of sorption isotherms using Langmuir and Freundlich models are summarized in Table 3. The data show that the removal process of dye was fitted well with the Langmuir isotherm. Further, the removal capacity of PANI and PANI@AC adsorbents toward MO are $49.50 \mathrm{mg} \cdot \mathrm{g}^{-1}$ and $192.30 \mathrm{mg} \cdot \mathrm{g}^{-1}$, respectively. The adsorption performance of the PANI@AC product toward MO was compared with that of other adsorbent materials in the literature as clarified in Table 4. Clearly, the PANI@AC product outperformed most of the adsorbents because it has the highest adsorption capacity value.

\subsection{Reuse of adsorbent}

Regeneration and reusability of an adsorbent is an important factor to assess the feasibility for workable applications. Therefore, this adsorbent product was used for several adsorption-regeneration cycles with removal over $60 \mathrm{~min}$. In this study, washing of employed adsorbent with $\mathrm{C}_{2} \mathrm{H}_{5} \mathrm{OH}$ and distilled $\mathrm{H}_{2} \mathrm{O}$ was used to regenerate the adsorbent PANI@AC. As shown in Fig. 3-d, the adsorbent show suitable capabilities for recovery and reuse. Besides, the adsorbent recovery at some steps showed a stable adsorbent capacity in dye removal which this result can illustrate that ethanol is an exceptional detergent for adsorbent recovery. Moreover, respectively. The continuous decrease in quantity adsorbed and reusability efficiency could 
suggest that some MO remained on PANI@AC after every reusability or that the adsorbent structure was modifying or changing.

\section{Conclusions}

In the present work, PANI@AC nanostructures were facilely synthesized by in-situ oxidative polymerization and used to remove MO dye from aqueous. The prepared adsorbents were characterized using FTIR, XRD, TGA and BET analyses, and effects of contact time and MO concentration were investigated in batch. Moreover, at $\mathrm{pH} 6.0,100 \mathrm{mg} . \mathrm{L}^{-1} \mathrm{MO}$ concentration, and $10 \mathrm{mg}$ adsorbent at $298 \mathrm{~K}$, the overall adsorption potential of PANI@AC was found to be $192.52 \mathrm{mg} \cdot \mathrm{g}^{-1}$. The process's adsorption, kinetics, and isothermal analysis were examined using various variables such as $\mathrm{pH}$, contact time and $\mathrm{MO}$ concentration. To pretend the adsorption kinetics, various kinetics models, included pseudo first order and pseudo second order were tested to the experiments data. The kinetic analysis revealed that the pseudo second order rate law performed better than the pseudo first order rate formula in promoting the formation of the chemisorption phase. In the case of isothermal studies, an analysis of measured correlation coefficient $\left(R^{2}\right)$ values revealed that the Langmuir model was a better match to experimental results than the Freundlich model. Additionally, the obtained PANI@AC adsorbent exhibited a acceptable cyclability to a range between $77.14 \%$ and $40.34 \%$ after 5 cycles.

\section{Acknowledgements}

Authors gratefully acknowledge the Algerian Ministry of Higher Education and Scientific Research, and also University Materials Science Institute of Alicante Spain for the co-operation availing. 
Funding information: There is no financial sources funding regarding of this study.

Conflict of Interest: The authors declare that they have no competing interests.

303

304

\section{References}

[1] T.A. Khan, R. Rahman, I. Ali, E.A. Khan, A.A. Mukhlif. Removal of malachite green from aqueous solution using waste pea shells as low-cost adsorbent-adsorption isotherms and dynamics. Toxicol. Environ. Chem., 96 (2014) 569-578.

[2] M. Tanzifi, S.H. Hosseini, A.D. Kiadehi, M. Olazar, K. Karimipour, R. Rezaiemehr, I. Ali. Artificial neural network optimization for methyl orange adsorption onto polyaniline nano-adsorbent: Kinetic, isotherm and thermodynamic studies. Journal of Molecular Liquids. 244 (2017) 189-200.

[3] M.U. Herrera, C.M. Futalan, R. Gapusan, M.D.L. Balela. Removal of methyl orange and copper (II) ions from aqueous solution using polyaniline-coated kapok (Ceiba pentandra) fibers. Water Sci. Technol., 78 (2018) 1137-1147.

[4] A.C. Lacuesta, M.U. Herrera, R. Manalo, M.D.L. Balela. Fabrication of kapok paper-zinc oxide-polyaniline hydrid nanocomposite for methyl orange removal. Surf. Coat. Technol., 350 (2018) 971-976.

[5] G. Annadurai, R. Juang, D. Lee. Use of cellulose-based wastes for adsorption of dyes from aqueous solutions. J. Hazard Mater., 92 (2002) 263-274. 
[6] P. Mokhtari, M. Ghaedi, K. Dashtian, M.R. Rahimi, M.K. Purkait. Removal of methyl orange by copper sulfide nanoparticles loaded activated carbon: Kinetic and isotherm investigation. Journal of Molecular Liquids. 219 (2016) 299-305.

[7] B.A.M. Al-Rashdi, D.J. Johnson, N. Hilal. Removal of heavy metal ions by nanofiltration. Desalination, 315 (2013) 2-17.

[8] S. Dashamiri, M. Ghaedi, K. Dashtian, M.R. Rahimi, A. Goudarzi, R. Jannesar. Ultrasonic enhancement of the simultaneous removal of quaternary toxic organic dyes by $\mathrm{CuO}$ nanoparticles loaded on activated carbon: Central composite design, kinetic and isotherm study. Ultrasonics Sonochemistry. 31 (2016) 546-557.

[9] A. Paz, J. Carballo, M.J. Perez, J.M. Dominguez. Biological treatment of model dyes and textile wastewater. Chemosphere. 181 (2017) 168-177

[10] S. Sachdeva, A. Kumar. Preparation of nanoporous composite carbon membrane for separation of rhodamine B dye. Journal of Membrane Science. 329 (2009) 2-10.

[11] A. Asfaram, M. Ghaedi, S Hajati, A. Goudarzi, A.A. Bazrafshan. Simultaneous ultrasound-assisted ternary adsorption of dyes onto copper-doped zinc sulfide nanoparticles loaded on activated carbon: Optimization by response surface methodology. Spectrochimica Acta Part A: Molecular and Biomolecular Spectroscopy. 145 (2015) 203-212.

[12] K. Dai, H. Chen, T. Peng, D. Ke, H. Yi. Photocatalytic degradation of methyl orange in aqueous suspension of mesoporous titania nanoparticles. Chemosphere. 69 (2007) 13611367 
[13] A. Asfaram, M. Ghaedi, S. Hajati, M. Rezaeinejad, A. Goudarzi, M.K. Purkait. Rapid removal of Auramine-O and Methylene blue by $\mathrm{ZnS}: \mathrm{Cu}$ nanoparticles loaded on activated carbon: A response surface methodology approach. Journal of the Taiwan Institute of Chemical Engineers. 53 (2015) 80-91

[14] C. Chen, Z. Gan, C. Xu, L. Lu, Y. Liu, Y. Gao. Electrosynthesis of poly(aniline-co-azure B) for aqueous rechargeable zinc-conducting polymer batteries. Electrochimica Acta. 252 (2017) 226-234.

[15] A. Guerfi, J. Trottier, C. Gagnon, F. Barray, K. Zaghib. High rechargeable sodium metalconducting polymer batteries. Journal of Power Sources. 335 (2016) 131-137.

[16] B.S. Dakshayini, K.R. Reddy, A. Mishra, N.P. Shetti, S.J. Malode, S. Basu, S. Naveen, A.V. Raghu. Role of conducting polymer and metal oxide-based hybrids for applications in ampereometric sensors and biosensors. Microchemical Journal. 147 (2019) 7-24

[17] S. Wang, Z. Wang, Y. Huang, Y. Hu, L. Yuan, S. Guo, L. Zheng, M. Chen, C. Yang, Y. Zheng, J. Qi, L. Yu, H. Li, W. Wang, D. Ji, X. Chen, J. Li, L. Li, W. Hu. Directly Patterning Conductive Polymer Electrodes on Organic Semiconductor via In Situ Polymerization in Microchannels for High-Performance Organic Transistors. ACS Applied Materials \& Interfaces. 13 (2021) 17852-17860.

[18] H. Kweon, A. Hosking, M. Mushfiq, M.M. Alam. Selective and Trace Level Detection of Hydrazine Using Functionalized Single-Walled Carbon Nanotube-Based Microelectronic Devices. ACS Applied Electronic Materials. 3 (2021) 711-719.

[19] A. Eftekhari. Nanostructured Conductive Polymers. John Wiley \& Sons (2011). 
[20] O. Mahi, K. Khaldi, M. S. Belardja, A. Belmokhtar, A. Benyoucef. Development of a New Hybrid Adsorbent from Opuntia Ficus Indica NaOH Activated with PANI Reinforced and Its Potential Use in Orange G Dye Removal. Journal of Inorganic and Organometallic Polymers and Materials. 31 (2021) 2095-2104.

[21] Y. Li, W. Nie, P. Chen, Y. Zhou. Preparation and characterization of sulfonated poly (styrene-alt-maleic anhydride) and its selective removal of cationic dyes. Colloids and Surfaces A: Physicochemical and Engineering Aspects. 499 (2016) 46-53.

[22] J. Li, Q. Wang, Y. Bai, Y. Jia, P. Shang, H. Huang, F. Wang. Preparation of a novel acid doped polyaniline adsorbent for removal of anionic pollutant from wastewater. Journal of Wuhan University of Technology-Mater. Sci. Ed. 30 (2015) 1085-1091.

[23] E.N. Zare, A. Motahari, M. Sillanpää. Nanoadsorbents based on conducting polymer nanocomposites with main focus on polyaniline and its derivatives for removal of heavy metal ions/dyes: a review. Environmental Research. 162 (2018) 173-195.

[24] Q. Hu, H. Liu, Z. Zhang, Y. Xie. Nitrate removal from aqueous solution using polyaniline modified activated carbon: Optimization and characterization. Journal of Molecular Liquids 309 (2020) 113057.

[25] L. Maaza, F. Djafri, A. Belmokhtar, A. Benyoucef. Evaluation of the influence of Al2O3 nanoparticles on the thermal stability and optical and electrochemical properties of PANIderived matrix reinforced conducting polymer composites. Journal of Physics and Chemistry of Solids. 152 (2021) 109970 
[26] F. Z. Kouidri, I. Moulefera, S. Bahoussi, A. Belmokhtar, A. Benyoucef. Development of hybrid materials based on carbon black reinforced poly(2-methoxyaniline): preparation, characterization and tailoring optical, thermal and electrochemical properties. Colloid and Polymer Science (2021). doi.org/10.1007/s00396-021-04837-2.

[27] A. Belalia, A. Zehhaf, A. Benyoucef. Preparation of Hybrid Material Based of PANI with $\mathrm{SiO}_{2}$ and Its Adsorption of Phenol from Aqueous Solution. Polymer Science, Series B. 60 (2018) 816-824.

[28] M. Zenasni, A.Q. Jaime, A. Benyoucef, A. Benghalem. Synthesis and characterization of polymer/V2O5 composites based on poly(2-aminodiphenylamine). Polymer Composites. 42 (2021) 1064-1074

[29] M.H. Sadeghi, M.A. Tofighy, T. Mohammadi. One-dimensional graphene for efficient aqueous heavy metal adsorption: Rapid removal of arsenic and mercury ions by graphene oxide nanoribbons (GONRs). Chemosphere. 253 (2020) 126647.

[30] A.B. Wozniak, R. Pietrzak. Adsorption of organic and inorganic pollutants on activated bio-carbons prepared by chemical activation of residues of supercritical extraction of raw plants. Chemical Engineering Journal. 393 (2020) 124785.

[31] S.C. Rodrigues, M.C. Silva, J.A. Torres, M.L. Bianchi. Use of Magnetic Activated Carbon in a Solid Phase Extraction Procedure for Analysis of 2,4-dichlorophenol in Water Samples. Water, Air, \& Soil Pollution. 231 (2020) 2-13.

[32] M.A. Bekhti, M.S. Belardja, M. Lafjah, F. Chouli, A. Benyoucef. Enhanced tailored of thermal stability, optical and electrochemical properties of PANI matrix containing $\mathrm{Al}_{2} \mathrm{O}_{3}$ 
hybrid materials synthesized through in situ polymerization. Polymer Composites. 42 (2021) 6-14.

404

405

406

407

408

409

410

411

412

413

414

415

416

417

[33] M. Javed, S.M. Abbas, M. Siddiq, D. Han, L. Niu, Mesoporous silica wrapped with graphene oxide-conducting PANI nanowires as a novel hybrid electrode for supercapacitor. Journal of Physics and Chemistry of Solids. 113 (2018) 220-228.

[34] T. Lindfors, A. Ivaska. $\mathrm{pH}$ sensitivity of polyaniline and its substituted derivatives. Journal of Electroanalytical Chemistry. 531 (2002) 43-52.

[34] B. Suna, Y. Yuan, H. Li, X. Li, C. Zhang, F. Guo, X. Liu, K. Wang, X.S. Zhao. Wastecellulose-derived porous carbon adsorbents for methyl orange removal. Chemical Engineering Journal 371 (2019) 55-63

[35] M. Duhan, R. Kaur. Adsorptive removal of methyl orange with polyaniline nanofibers: an unconventional adsorbent for water treatment. Environmental Technology. 41 (2020) 2977-2990.

[36] L. Aia, J. Jiang, R. Zhang. Uniform polyaniline microspheres: A novel adsorbent for dye removal from aqueous solution. Synthetic Metals. 160 (2010) 762-767.

[37] J. Ma, F. Yu, L. Zhou, L. Jin, M. Yang, J. Luan, Y. Tang, H. Fan, Z. Yuan, J. Chen. Enhanced Adsorptive Removal of Methyl Orange and Methylene Blue from Aqueous Solution by Alkali-Activated Multiwalled Carbon Nanotubes. ACS Applied Materials \& Interfaces. 4 (2012) 5749-5760. 
[38] A. Sanchez-Sanchez, F. Suarez-Garcia, A. Martinez-Alonso, J.M.D. Tascon, Synthesis, characterization and dye removal capacities of N-doped mesoporous carbons, J. Colloid Interface Sci. 450 (2015) 91-100.

[39] R.H. Huang, Q. Liu, J. Huo, B.C. Yang, Adsorption of methyl orange onto protonated crosslinked chitosan. Arabian Journal of Chemistry. 10 (2013) 24-32.

[40] D. Robati, B. Mirza, M. Rajabi, O. Moradi, I. Tyagi, S. Agarwal, V. Gupta, Removal of hazardous dyes-BR 12 and methyl orange using graphene oxide as an adsorbent from aqueous phase. Chemical Engineering Journal. 284 (2016) 687-697.

[41] Y. Haldorai, J.-J. Shim, An efficient removal of methyl orange dye from aqueous solution by adsorption onto chitosan/ $\mathrm{MgO}$ composite: a novel reusable adsorbent. Applied Surface Science. 292 (2014) 447-453.

[42] R.B. Gapusan, M. Donnabelle, L. Balela. Adsorption of anionic methyl orange dye and lead(II) heavy metal ion by polyaniline-kapok fiber nanocomposite. Materials Chemistry and Physics. 243 (2020) 122682.

[43] L.S.M. Rodríguez, L.M.G. Rodríguez, J.J.A. Espinoza, A.E.C. Guajardo, J.C.M. Llamas. Synthesis and characterization of a polyurethane-polyaniline macroporous foam material for methyl orange removal in aqueous media. Materials Today Communications. 26 (2021) 102155.

[44] Y. Xiao, J.M. Hill. Benefit of hydrophilicity for adsorption of methyl orange and electroFenton regeneration of activated carbon-polytetrafluoroethylene electrodes. Environmental Science \& Technology. 52 (2018) 11760-1176. 
443 Fig. 1. The proposed pathway of synthesis and of MO removal by PANI@AC

444 Fig. 2. (a) : X-ray diffraction (XRD) patterns ; (b) : FT-IR adsorption spectra ; (c) :

445 Thermogravimetric analysis obtained in $\mathrm{N}_{2}$ atmosphere at $10^{\circ} \mathrm{C} \cdot \mathrm{min}^{-1}$ and (d) : $\mathrm{N}_{2}$ adsorption446 desorption isotherm of adsorbents materials fabricated.

447 Fig. 3. (a): Effect of pH on the adsorption capacity of MO on PANI and PANI@ AC materials 448 (adsorbent dose: 10 mg; MO: 25 mL; T: 298 K); (b): Contact Time (Co: 100 mg.L ${ }^{-1}$; pH: 6.0; T: 449 298K; adsorbents dose: $10 \mathrm{mg}$ ); (c): Adsorption isotherms of MO by PANI and PANI@AC 450 materials (adsorbent dose: $10 \mathrm{mg}$; MO: $25 \mathrm{~mL}$; T: $298 \mathrm{~K}$; pH: 6.0) and (d): Adsorbent capacity 451 changes and initial MO in consecutive cycles (adsorbent dose: $10 \mathrm{mg}$; MO: $25 \mathrm{~mL}$; T: $298 \mathrm{~K}$; 452 pH: 6.0). 
Figures

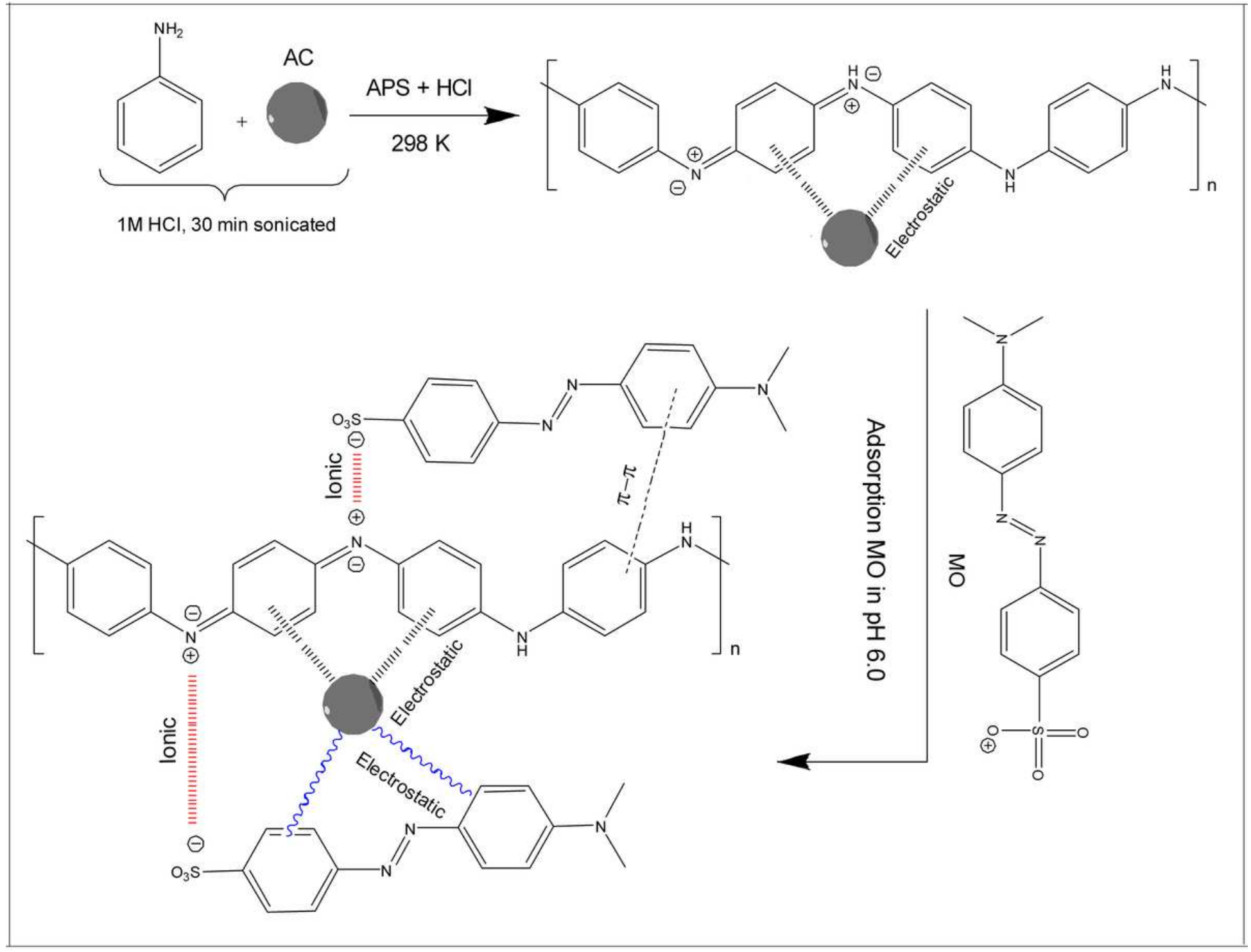

Figure 1

The proposed pathway of synthesis and of MO removal by PANI@AC 


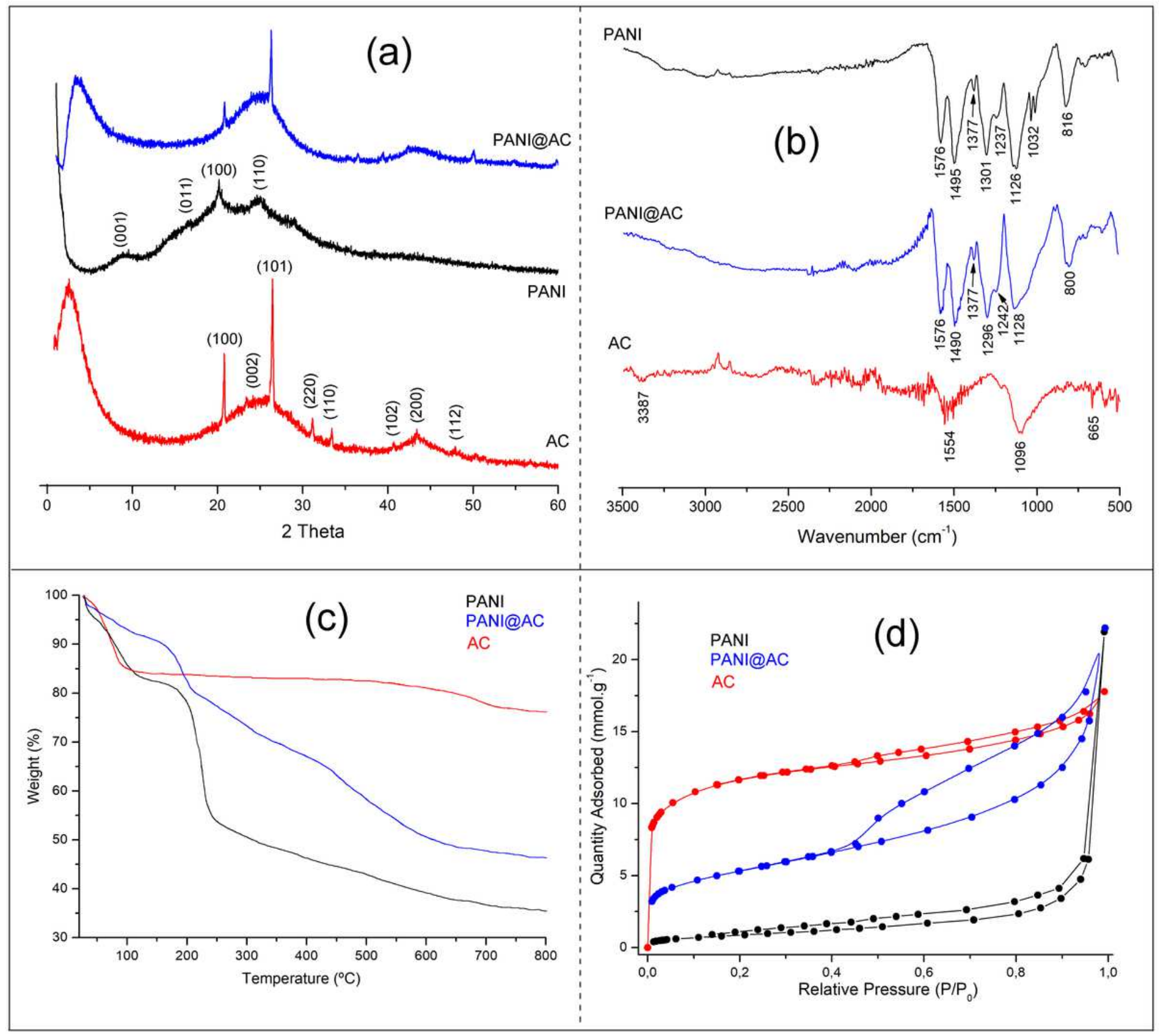

Figure 2

(a) : X-ray diffraction (XRD) patterns ; (b) : FT-IR adsorption spectra ; (c) : Thermogravimetric analysis obtained in N2 atmosphere at $10^{\circ} \mathrm{C}$.min-1 and (d) : N2 adsorption-desorption isotherm of adsorbents materials fabricated. 


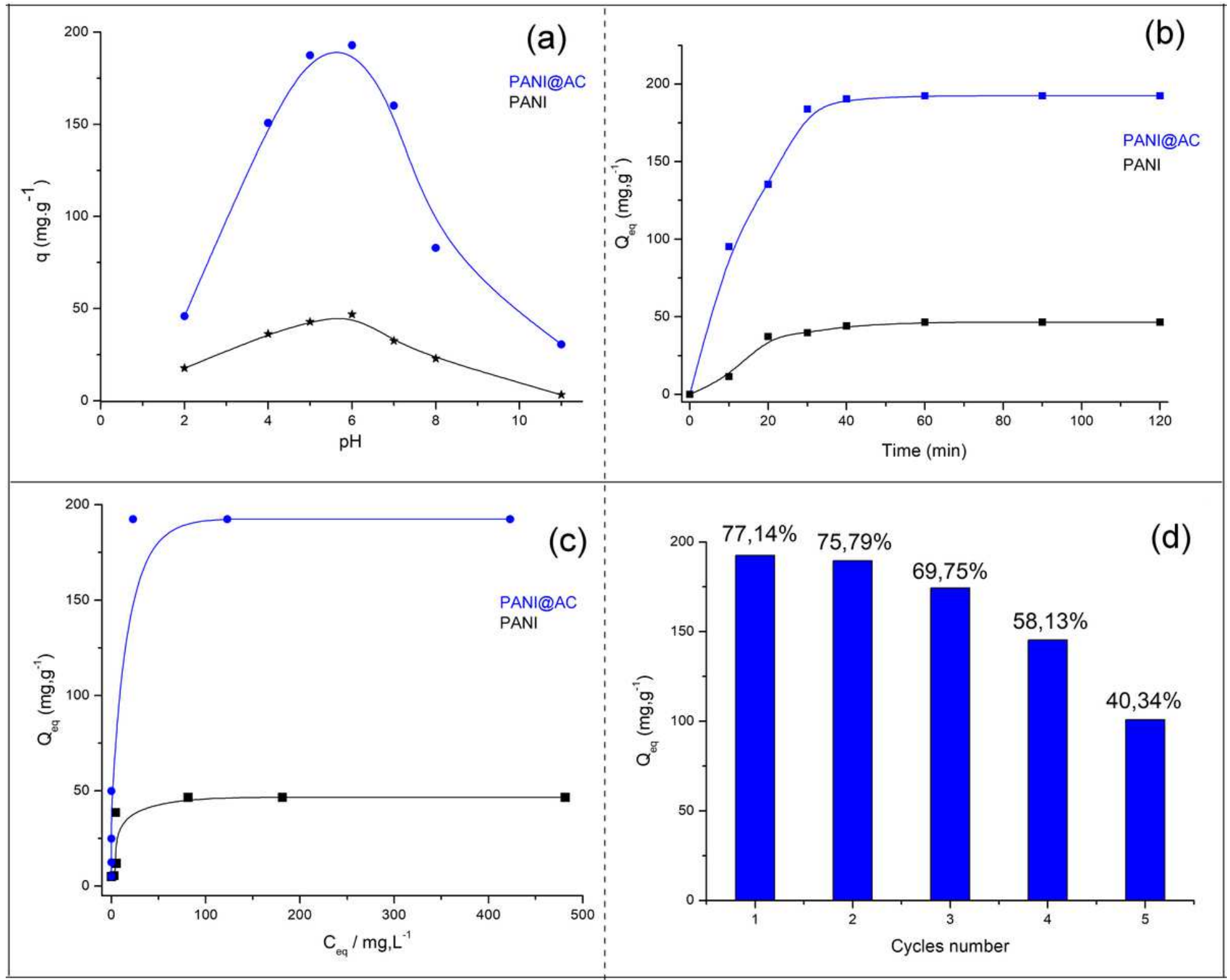

Figure 3

(a): Effect of pH on the adsorption capacity of MO on PANI and PANI@AC materials (adsorbent dose: 10 mg; MO: 25 mL; T: 298 K); (b): Contact Time (C0: 100 mg.L-1; pH: 6.0; T: 298K; adsorbents dose: 10 mg); (c): Adsorption isotherms of MO by PANI and PANI@AC materials (adsorbent dose: 10 mg; MO: 25 mL; T: $298 \mathrm{~K} ; \mathrm{pH}: 6.0)$ and (d): Adsorbent capacity changes and initial MO in consecutive cycles (adsorbent dose: 10 mg; MO: 25 mL; T: 298 K; pH: 6.0). 